\title{
Migration Patterns in Duhok Governorate, Iraq, 2000-2010
}

\author{
Lina Eklund* and Petter Pilesjö
}

\begin{abstract}
Center for Middle Eastern Studies and Department of Physical Geography and Ecosystem Science, Lund University,
\end{abstract} Sweden

\begin{abstract}
Most migration literature focuses on large scale movements of people across country borders, while the internal migration trends of countries are commonly neglected, despite the fact that the understanding of internal migration trends is crucial for planning the future for a country. In Iraq a major reason for migration has been security - a direct result of its turbulent history since the 1980's. More recently, the Kurdistan Region in Iraq has stabilized which has led to more voluntary population movements, such as economic migration. This paper seeks to investigate the internal and external movements in Duhok Governorate, Kurdistan, Iraq, during the past decade. This is done by looking at reasons for migration, characteristics of the migrants, and the time for migration. Data on migration, environment, and rural livelihoods were collected through 606 interviews in rural villages in Duhok Governorate. Additionally, 600 interviews were conducted in the urban areas of Duhok, Semel, Zakho, and Amedi, in order to capture the rural to urban migration. The study found economic reasons to be the main motivation for migration, closely followed by family/marriage. Contradicting common notions of urbanization, there is a trend of urban to rural migration for households. Individuals, however, are more prone to migrate abroad or from rural to urban areas. Environmental migration is low and can be explained by the low dependence on agriculture in the region.
\end{abstract}

Keywords: Economic migration, environmental migration, Iraq, Kurdistan, migration patterns, urbanization.

\section{INTRODUCTION}

Movements of people have taken place throughout the human history. People have migrated in search of better lives in terms of economy, security, or to escape insecurities such as conflicts or environmental degradation [1]. Although people today migrate mainly for the same reasons, the scale and extent of movements have increased due to globalization and improved mobility.

Since 1973 to the early 1990 's, migration patterns in the Middle East and North Africa (MENA) region have been dominated by labor migration from poorer countries to the oil states in the Gulf [1]. Additionally, conflicts and political instability in the region have caused a high degree of forced migration, both within and from the MENA region.

Contemporary Iraq has a history of violence and conflict, starting with the Iraq-Iran war in 1980-1988, continuing with the invasion of Kuwait in 1991, and the first Gulf war as a consequence of the invasion [2]. Before the war in the 1980 's, Iraq was a country of immigration, mainly attracting contract workers. In the last 30 years this trend has been reversed, and today Iraq is a country of emigration. In 1990, Iraq was sanctioned by the United Nations and since then the country has suffered from extreme unrest and instability, for example the Shiite uprising in 1991 and Saddam Hussein's bombings of Kurdish towns in the same year. The two main Kurdish parties, Patriotic Union of Kurdistan (PUK) and Kurdistan Democratic Party (KDP), have also had several

*Address correspondence to this author at the Center for Middle Eastern Studies and Department of Physical Geography and Ecosystem Science, Lund University, Sweden; Tel: +46-462229609;

E-mails: Lina.Eklund@nateko.lu.se, linaeklund@gmail.com clashes causing insecurity in the Kurdish parts of Iraq. All these events, in combination with poverty, human rights abuses, and an uneven distribution of wealth, have caused what Sirkesi [3] calls an "Environment of Insecurity", likely to increase migration and mobility. The most recent war led by the US, starting in 2003, introduced a new decade of violence which included a wave of sectarian violence after the bombing of the Al-Askari mosque in Samarra 2006.

Castles and Miller [1] state that between 1990 and 2002 approximately 1.5 million people left Iraq because of the Gulf War and the oppressive regime of Saddam Hussein. The US invasion of Iraq induced a second wave of displacement, in which 2.2 million Iraqis were forced to leave the country by 2007, and more than 2 million were estimated to be displaced within Iraq [3]. In March 2008, the International Organization for Migration (IOM) assessed that 2.7 million Iraqis had been displaced within Iraq and 1.5 million of them had been displaced after February 2006 (the bombing of the Al-Askari mosque) [4].

\subsection{Migration Theories}

Lee [5] defines migration as "a permanent or semipermanent change of residence", a broad definition that gives no restrictions on spatial distance of move, or if it is voluntary or forced. It is commonly associated with international movements of people, a phenomenon that creates both problems and opportunities in the world. Most migration and mobility studies are focused on this international migration, while fewer focus on the national or even local movements of people. In many countries, the internal migration is even larger than the international, and often the two types of migration are linked so that ruralurban migration might be a prelude to international migration $[1,6]$. 
Today, migration is closely related to economy, and accordingly there are several economic theories of migration. One particularly influential economic theory is the Neoclassical theory, which attributes the individual decision to migrate to "rational comparison of the relative costs and benefits of remaining at home or moving" $[1,7]$. This approach is also sometimes referred to as 'push and pull' theory. The Neoclassical theory however neglects other factors, such as government restrictions, or the fact that migrants do not always know exactly the wage levels or employment opportunities of the potential destination.

Migration systems theory is an interdisciplinary approach that seeks to bridge the different disciplines within migration studies [1]. It focuses on the links between countries within the system: of sending and receiving countries. The migration decision is the result of "interacting macro- and microstructures", where macrostructures are external factors on a national or international level such as political economy, relationships between states, or migration laws. In contrast, microstructures are factors at the individual or migrant group level, which include social networks or family ties [1]. The family and community have proven to play an important role in migration decisions, and these ties often provide the migrants with both financial and social capital. Social networks facilitate the migration process by providing safety and valuable information, and one migration movement usually increases the chance of a subsequent migration $[1,8]$.

One of the many consequences of climate change is that some parts of the earth is likely to become less habitable with the projected increases in storms, intense rainfalls, floods, and other extreme weather events, leading to mass migrations of people. The Intergovernmental Panel on Climate Change (IPCC) noted in 1990 that climate change might have the greatest impact on human migration [9]. Laczko and Aghazarm [10] describe four ways in which climate change can affect migration:

1. Intensification of natural disasters leading to forced displacement

2. Increased warming and drought leading to negative effects on agricultural yields and water access

3. Sea level rise that makes coastal areas inhabitable and might even put islands under water

4. More competition over natural resources could lead to increased conflicts, that in turn can cause displacement

A distinction is commonly made between slow onset disasters, such as drought or land degradation, and quick onset disasters, such as hurricanes or floods [10]. The former usually leads to voluntary migration, often related to economic reasons, while the latter is more likely to lead to involuntary displacement. Migration is not just the result of environmental degradation pushing people away. Economic, social, or environmental pull factors are commonly involved. In order for migration to happen, some financial and social capital is also required, meaning that some people, perhaps the most vulnerable, will not be able to migrate even though they need to.

Urbanization is a process containing three main components: urban population growth (i.e. higher birth rates than death rates), urban expansion, and rural/semi-rural to urban migration $[11,12]$. Urban management has been described as "one of the most important challenges of the 21st century" [11]. According to the United Nations Department of Economic and Social Affairs [13] approximately $50 \%$ of the world's population today live in urban areas, and by 2030 this number is expected to have reached $60 \%$. In Iraq, the urban population already makes up $66 \%$ of the total population, and in 2030 it is expected to be almost 70\% [13]. United Nations Assistance Mission for Iraq (UNAMI) reported in 2011 that the recent drought that struck Iraq has exacerbated water scarcity for drinking water and agriculture, leading to rural-urban migration [14]. This trend is however expected to slow down with improved water resource management that would enhance agricultural livelihoods.

\subsection{Objectives}

Most migration research on the Middle East focuses on international migration flows, mainly from The Middle East and North Africa (MENA) to western countries, which means that there is a lack of research on the regional or national migration patterns $[1,6]$. In order to capture the complex patterns of migration it is important to consider both internal and external migration, and understand the drivers for these movements. Migration has both transnational and national impacts on demography and development [15-17]. It shapes societies via sociological, economic, political, and cultural interactions, and is thus a powerful phenomenon with far reaching effects. To facilitate the rebuilding of the new Iraq it is important to know the demographic trends and where to invest in social and economic development. Migration can potentially highlight social or economic inequality, and in order to predict the future demographics, it is crucial to document and study the patterns of today.

This study is an initial part of a more comprehensive study of the demographic trends in Iraq. The overall aim of this larger study is to discuss and analyze the need for investment in development for the re-organization of Iraq. Due to lack of data and the fact that no research has been conducted on the small scale migration patterns in the Middle East, this initial investigation will focus on providing information and directions for future research. Also, in the discussion of migration and demography, the question of climate change and environmental problems is a key issue with increasing importance, not the least in areas where water is limited, like the Middle East.

The objectives of this study are therefore to:

- Investigate the main patterns and trends of migration and demography in Duhok Governorate, Iraq, during the last ten years, in order to provide a foundation for future research.

- To discuss the importance of different determinants of migration, such as economy, security, family and environment in the Kurdish and Iraqi society.

- To bridge some of the gaps in migration research, providing more detailed information on both internal and external migration trends within Iraqi Kurdistan.

With reference to the objectives, some specific questions have been addressed. First of all, the spatial migration patterns require investigation, i.e. where people migrate from and to where. Furthermore, the migrant characteristics need 
to be explored; are they households or individuals? Women or men? What reasons do people report for their migrations, and does environmental degradation have effects on the migration decision? We try to respond to these questions in order to give a descriptive presentation of the contemporary migration patterns of Duhok Governorate, Iraq.

\section{DATA AND METHODOLOGY}

\subsection{Study Area}

Iraqi Kurdistan Region consists of Duhok, Erbil and Sulaymaniyah Governorate (see Fig. 1), and is an autonomous region administered by the Kurdistan Regional Government since 1992, when the first elections for the parliament were held [18]. Before the region became autonomous, there were several conflicts between the Iraqi government and the Kurdish representative parties, resulting in mass expulsions of 200,000 Kurds in 1971-1980, the Anfal genocide campaigns in 1987-1989, and the displacement of $80 \%$ of the Kurdish population between 1961 and 1992 [18, 19]. From 1994 to 1998 there was a civil war between the two main parties, Kurdistan Democratic Party (KDP) and the Patriotic Union of Kurdistan (PUK). These years of war and post-war have induced emigration of the working population and well educated people from all sectors in Kurdistan.

The $165,000 \mathrm{~km}^{2}$ that constitutes the Kurdistan region are the most fertile part of Iraq due to its relatively high annual precipitation [19]. United Nations Development Programme (UNDP) divides the Kurdistan region into three main "physiographic zones": (a) The Northern Range of the
Zagros Mountains, (b) The Central Range of the Border Folds, and (c) The Northern Plains of the Tigris River. The climate in the plains is semi-arid, but in general Kurdistan has snowy, cold winters, and dry, warm summers. October to May is the main precipitation period, and the annual average rainfall is $700 \mathrm{~mm}$, with variations between 100 and 1,300 $\mathrm{mm}$. Surface water resources are mainly fed by rainfall and snow, and make up about 18 billion $\mathrm{m}^{3}$ in the region. Main waters in Kurdistan are the rivers Khabur, Greater Zab, Lesser Zab, Sirwan, and Awa Spi, and artificial lakes and impoundments, such as Lake Dokan, Derbandikhan Dam, and Duhok Impoundment.

Duhok Governorate consists of four districts (Fig. 1): Amedi, Duhok, Semel and Zakho [4]. However, the Kurdistan Regional Statistics Office counts another three, and in total seven, districts to Duhok Governorate [20]. This inconsistency makes population estimations difficult, but the FAO Rural Household Survey reports a population of 783,000 people in Duhok Governorate (in the four districts) for 2003 [21]. COSIT, the Iraq statistics office, also presents an estimate (based on the 1987 census) of 968,901 people in Duhok Governorate for the year 2009 [22].

A rural household survey was conducted in July 2011, and an urban household survey was conducted in September 2011. The rural sites were villages of between 4 and 500 households, distributed over the four districts of Duhok Governorate (Fig. 1). The rural areas of Duhok Governorate are characterized by small agricultural villages with either cereals or orchards. Most households have water, electricity, and cars, but the infrastructure, e.g. roads, is of poor quality.

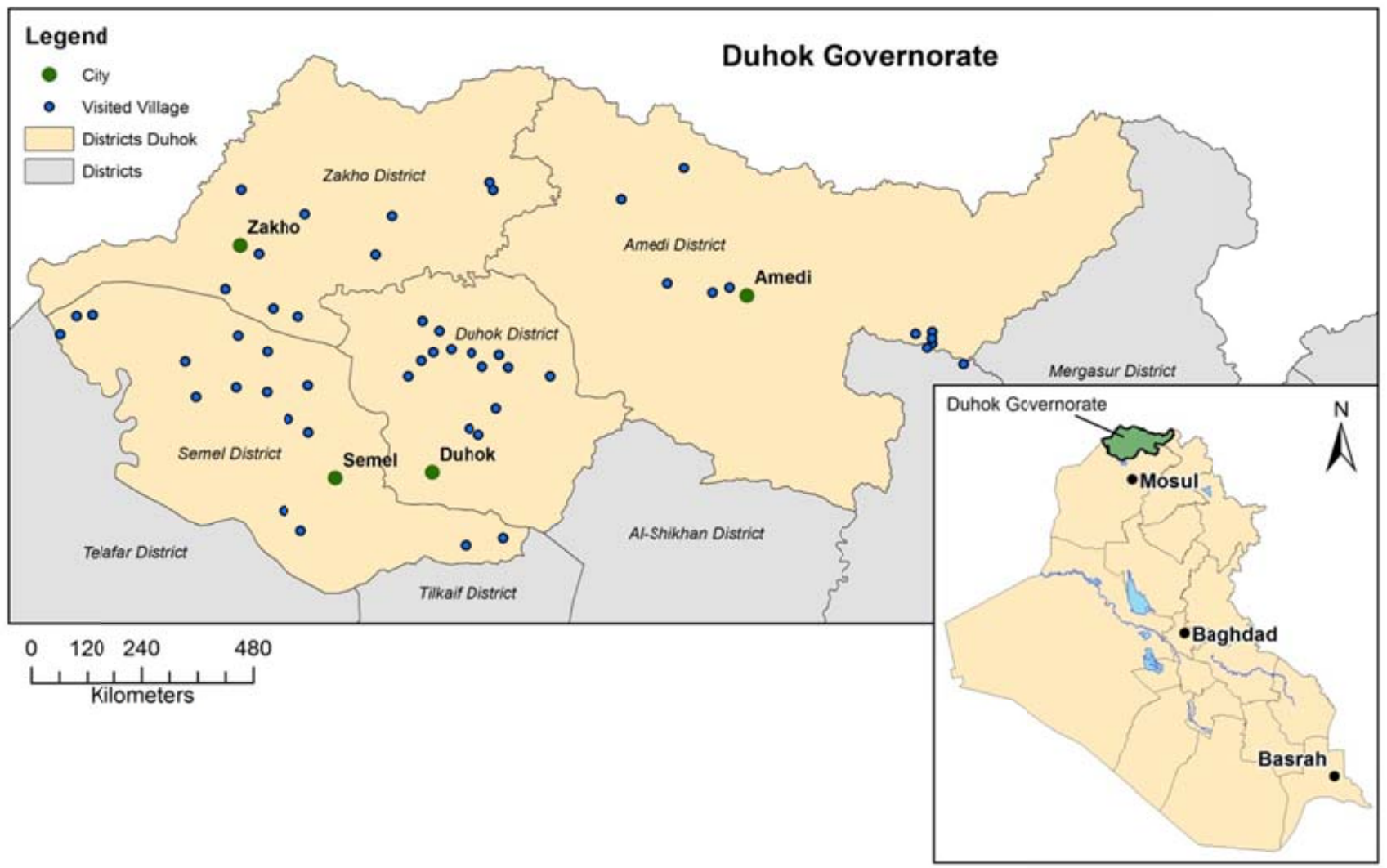

Fig. (1). Study area. 


\subsection{Field Data Collection}

The field work was conducted July to September 2011 in Duhok Governorate, Iraq. The work was divided into three parts: map data collection, interviews with rural villagers, and interviews with urban residents.

\subsubsection{Map Data}

The map data were collected from two international organizations: IOM and United Nations' Information and Analysis Unit (IAU). The data collected and used in this study were:

\section{- $\quad$ Administrative boundaries of Iraq \\ - Cities \\ - $\quad$ Villages \\ - $\quad$ Rivers and water bodies}

\subsubsection{Rural Household Survey}

The survey held 38 questions about agriculture, socioeconomic properties of the household, environment, and migration. Most questions were close ended, but there were a few open ended questions. The migration part of the survey included questions about whether the household had migrated in the past 10 years, and if any household member had left to live elsewhere. Thus, data on household migration were obtained from the first hand source, while data on individual migration were obtained from a second hand source. A multiple response question about the reasons for migration was also included for both households and individuals. The survey was based on material from Bilsborrow's Collecting data on the migration-environment nexus [23], and FAO's Rural Household Survey in Iraq [21]. The questions were focused on the period between 2000 and 2010.

Six local field assistants, divided into two groups with one car for each group, carried out the interviews. For each day, six main villages from one of the four study area districts were randomly sampled. In addition to that, six "backup" villages were sampled, in case the first choice villages were unavailable, or abandoned. The six villages were divided so that each of the two groups of field assistants was instructed to visit three first choice villages, or, if needed, up to three "backup" villages. The division was based on the geographical locations of the villages, so that the group would visit villages not too far from each other. Geographical Information Systems (GIS) were used to locate villages, and to determine the above mentioned divisions. The field assistants conducted approximately 10 interviews per day, three interviews in each of the two first villages, and four in the last village of the day. Within the villages, the households were sampled in situ, by starting from the main road, dropping a pen and following the direction that the pen points to. Then interviews were conducted with every third household encountered. The field work resulted in 606 interviews, conducted in 51 villages (Table 1).

\subsubsection{Urban Household Survey}

The urban household survey questions were similar to the rural household survey, but had been modified to fit urban areas, and, hence, only had 19 questions. Questions about agriculture were removed, and the main focus was on migration and household profile. Urban households were interviewed in the four main cities of the four districts: Duhok, Amedi, Zakho and Semel. This survey was conducted to capture the "to urban" and individual "from urban" migration. Four field assistants conducted interviews based on the same sampling strategy as in the rural areas. The field work resulted in 600 interviews (Table 2).

Table 1. Distribution of Interviews in Rural Areas

\begin{tabular}{|c|c|c|}
\hline District & No. of Villages Visited & No of Interviews \\
\hline \hline Duhok & 16 & 216 \\
\hline Amedi & 11 & 120 \\
\hline Zakho & 10 & 120 \\
\hline Semel & 14 & 150 \\
\hline Sum & $\mathbf{5 1}$ & $\mathbf{6 0 6}$ \\
\hline
\end{tabular}

Table 2. Distribution of Interviews in Urban Areas

\begin{tabular}{|c|c|}
\hline City & No of Interviews \\
\hline \hline Amedi & 95 \\
\hline Duhok & 205 \\
\hline Semel & 150 \\
\hline Zakho & 150 \\
\hline Sum & $\mathbf{6 0 0}$ \\
\hline
\end{tabular}

\subsection{Data Compilation}

Instead of having a quantitative statistic approach and analysis, we have chosen to work initially with a quantitative descriptive approach. Our aim is to see the big patterns, and not only focus on statistically significant relations. Future research will deal with more in depth analytical and statistical studies of the collected data.

All migration events were sorted into the two categories "household migration" and "individual migration". To find the reasons for migration, all reported reasons were counted, and in cases where an individual or household had migrated for more than one reason, these reasons were all counted as equally important. This was done because it was not possible to determine whether one reason was more important than the other. Thus, there are more migration reasons than actual migration events. A bar graph was created to highlight the differences between household, male and female migration. To show the differences in migration flows and migration reasons over time, all reasons were sorted by year. A chart was produced showing the three main reasons for migration over time.

The origins and destinations for migration were used to detect the types of migration, e.g rural-rural or urban-rural. Urban areas were determined by checking a list of 260 Iraqi cities [24]. The ones on the list were defined as "Urban", while the communities not on the list were defined as "Rural". These migration types were sorted into a table for "individual migration" and "household migration". 
All migration destinations and origins that were connected by three or more migration events (either households or individuals) were presented in two migration pattern maps, one for households and one for individuals. The purpose of the maps was to show different spatial patterns of individual and household migration. The maps were created using a simple background map, compiled in ArcGIS 10, and then adding arrows and numbers in Inscape $[25,26]$.

Migration events from Baghdad and Mosul to Duhok Governorate were specifically sorted out and inserted into a chart to show changes over time. The reasons for leaving Baghdad or Mosul for Duhok were also noted.

In order to investigate whether or not there had been any environmental related migration, the number of events where "environmental degradation" had been a reason was counted. Furthermore, the amount of people likely to be vulnerable to environmental degradation, i.e. people that rely on agriculture for their livelihoods, was estimated and presented in a chart.

\section{RESULTS AND DISCUSSION}

For all 1206 households in the survey, there were 1033 migration events, including household, individual, and temporary migration. The rural household survey identified $165(27 \%$ of surveyed rural households) household migration events, and 113 (19\%) individual migration events. For urban household migration there were 626 (104\% of surveyed urban households) migration events, and $129(22 \%)$ for individuals. Out of the 626 household migration events, 520 represented temporary relocations (both ways) from the cities of Duhok, Semel or Zakho to rural villages in the vicinity, with return migration approximately a month later. The out-migration of this type happened in mid-March 2003, and the reported reason for this was unambiguously security. The time for migration coincides with the US invasion of Iraq (March 20, 2003), which could be an explanation for the increased instability that led to the relocations. This migration type has been excluded from the charts presented below, leaving 106 household migration events $(18 \%$ of surveyed urban households) recorded in urban areas, since it is not a

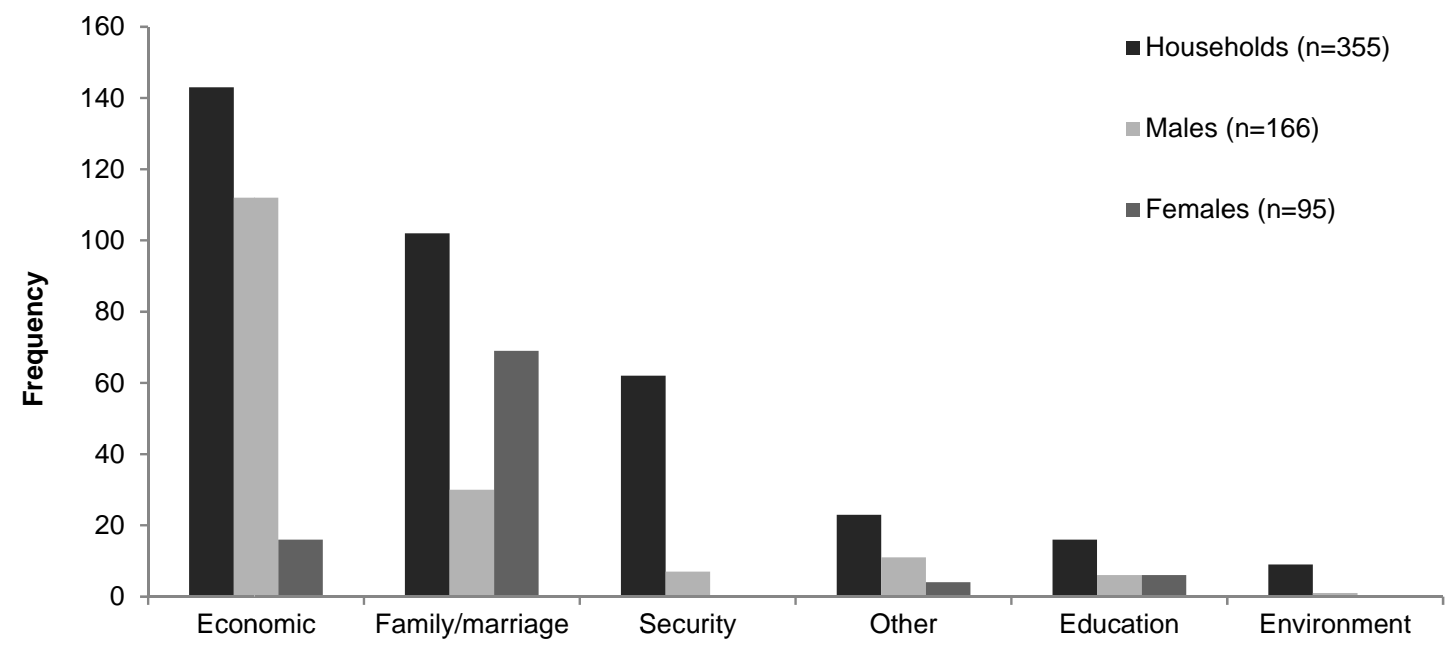

Fig. (2). Reasons for migration according to respondents (multiple reasons were allowed and chosen from a list). temporary or long term migration that can be comparable to other migration events. The percentages (between 18 and $27 \%$ ) represent a quite high mobility for both urban and rural populations in Duhok Governorate. None of the four groups seems particularly more mobile than the others, indicating that both households and individuals, rural and urban are all just as prone to migrate.

\subsection{Drivers of Migration}

For households and individual migrants, the most commonly reported reason for migration is economy, just as many migration theories suggest (Fig. 2). Economy is a quite broad term and could involve several kinds of reasons, e.g. job opportunities, cheaper housing, or agricultural yield loss. The second most important reason is family or marriage, possibly indicating the importance of family and marriage in the Kurdish and Iraqi culture. Security is a fairly common reason for households to migrate, but not as important for individuals. An explanation for this could be that security risks (e.g. conflicts) concern the whole family and should therefore lead to a migration of the whole household, instead of just one of the household members. Female migration is mainly for family/marriage reasons, but the second largest reason for female migration is economy. This indicates that there are job opportunities for females leading to their migration. For male migration the situation is the opposite, with economy as the most common reason and family/marriage as the second most common reason. Migration related to family reunions or marriage is mentioned in other migration literature (e.g. [27]), but is usually not considered to have as high importance as indicated by this study's results. Migration research often connects family or marriage migration to female migration, which is also seen in the results of this study. Females are more prone to move to their partners after marriage than men are, but family/marriage migration is still the second most important migration type for men.

When it comes to internal or national migration, the household's or individual's decision to migrate is likely to include a "rational comparison", as described in the Neoclassical theory (Section 1.2). First of all, within the country, most laws and regulations are the same which 
means that one element of uncertainty is eliminated. Furthermore, a short move within the country is likely to lead to far less culture shock than moving to e.g. another continent. It is also more probable that the migrating household or individual has relatives or friends in a destination area within the country, and/or that they have even visited the place before. To conclude, it is possible to have much more information to rationally compare the possible destination with the present resident area if the possible destination lies within the same country. A common criticism to the neoclassical theory is that international migrants usually lack the information to do this rational comparison, but for internal migration the neoclassical theory might be more valid.

\subsection{Year of Migration}

All years (2000-2010) have had less than 80 migration events, not counting the temporary security migration of 2003. Looking into the different reasons for migration over time, economy and family/marriage are the most important reasons, with economic reasons peaking at around 2007 and family/marriage reasons showing a fluctuating but possibly increasing trend (Fig. 3). Most migration events happened in the Kurdistan region, a bit further away from Baghdad where the center of conflict has been. This could help explaining the fact that economic and family/marriage migration were generally higher than security migration.

There is a distinct increase in security migration between the years 2002 and 2008, most likely related to the U.S. invasion of Iraq and the turmoil that followed.

The significant drop in the security migration type from 2006 to 2007 marks a change in stability and indicates that the situation has become less threatening. However, the major political happening in 2006 - the bombing of the AlAskari Mosque - should have created even more insecurity. In spite of that, population mobility did not increase but might instead have decreased.

\subsection{Origin and Destination}

The majority of the household migration events (36.7\%) have been of the type "Urban to Rural" (Table 3). Households moving from urban communities choose more often to settle in rural areas than in other urban centres. There have been informal sources reporting an increased rural-urban migration in Duhok governorate, where households move to the city, mainly to gain economic opportunities. However, the results in this study indicate that the trend is the opposite. This implies that there might be more economic opportunities in rural areas, for example more jobs or cheaper houses, than in the urban centers of Duhok, Semel, Zakho and Amedi.

Individuals tend to migrate more from rural to urban areas, supporting the urbanization theories. Although approximately $67 \%$ of all individual migration have been directed abroad, the majority of the internal individual migration have been of the type rural-urban (Table 3). An explanation for this could be that for households the best and safest opportunities are in rural areas, while individuals often want to try their luck in the cities.

In cases where households leave rural communities, half of those have moved to other rural communities, and the other half have moved to urban communities. The majority of the households migrating back from abroad to Duhok Governorate move to urban areas rather than rural.

According to the results, individuals tend to move abroad more than households. It is probable that individuals are more mobile than whole households, especially the individuals who are young and unmarried, and hence not that "tied up". However, this survey had little opportunity to cover the out-migration of households because of the limited study area. This will be discussed further in Section 3.6.

The household migration pattern map (Fig. 6) shows a large migration to Duhok and Zakho. The largest migration connection is however the one between Zakho and the

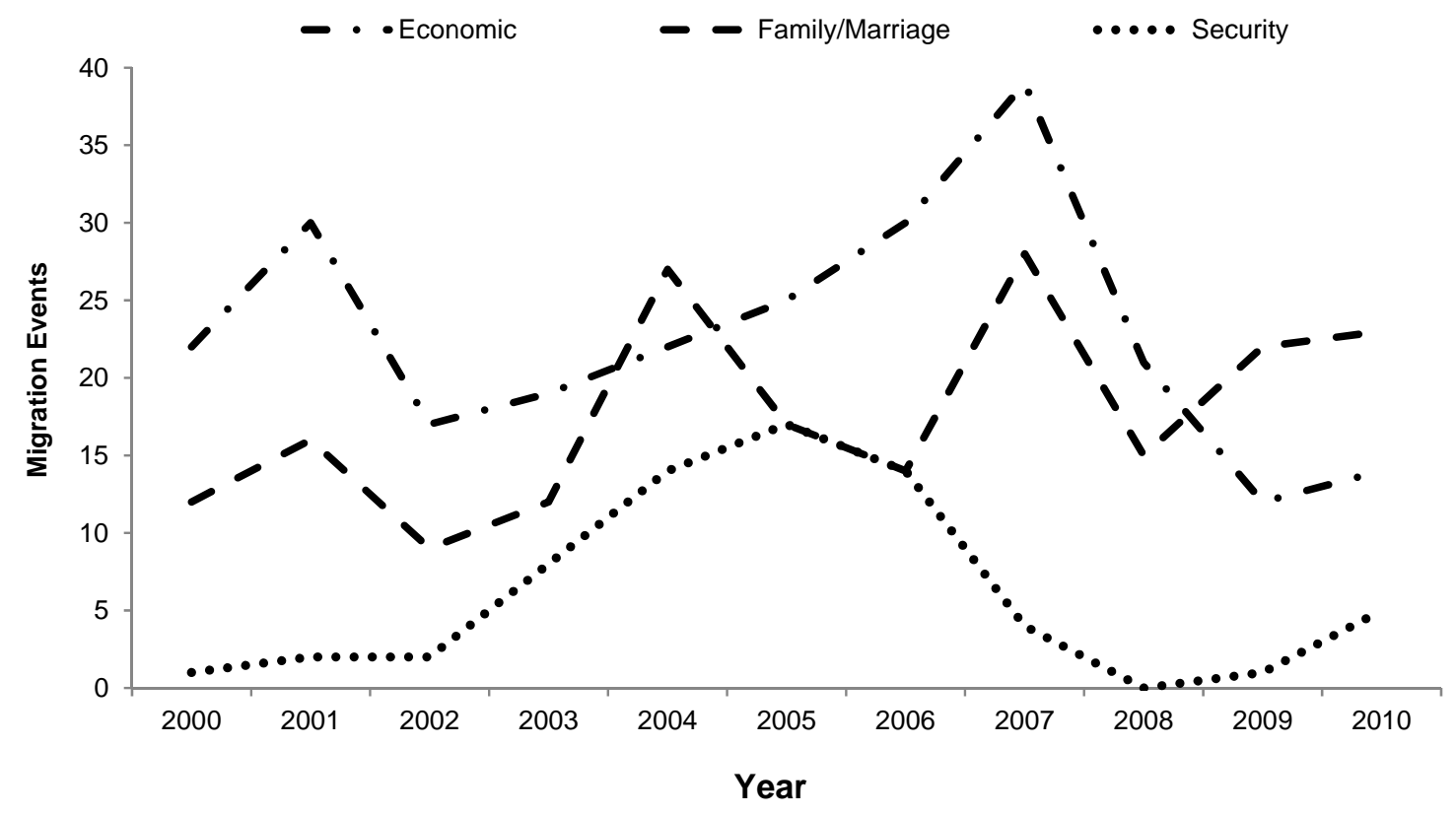

Fig. (3). The three main reported reasons for migration during the years 2000-2010. 
nearby village Charmsirmo, where 12 households migrated during the 10 year period. There is a large in-migration (total 17) from Baghdad to Shkafdla and Mergasur (in Duhok Governorate), while fewer households from Baghdad choose to move to Duhok city. This strong connection between Baghdad and the two villages indicates a situation where one or more households have started to migrate there, and then others have followed.

Individual migration patterns (Fig. 5) show a large outmigration to other countries, mainly Europe. Sweden and Germany are the main receivers of individual migrants, most possibly because of the large Kurdish communities in those countries, but the immigration policies of the countries might also play an important role. The domestic migration is small and mainly directed to the cities of Duhok and Zakho.

The migration pattern maps show connections between destination and origin, or "migration systems" as described in the introduction (see Section 1.1). A comparison between the two migration patterns maps (Figs. 4, 5) shows that household migration is more common within Duhok
Table 3. Types of Origin and Destination for Households' and Individuals' Migrations

\begin{tabular}{|c|c|c|c|c|}
\hline Type & Household & $\mathbf{\%}$ & Individual & $\mathbf{\%}$ \\
\hline \hline Abroad - Rural & 3 & 1.1 & 0 & 0.0 \\
\hline Abroad - Urban & 16 & 6.0 & 0 & 0.0 \\
\hline Rural - Abroad & 0 & 0.0 & 39 & 19.6 \\
\hline Rural - Urban & 54 & 20.2 & 29 & 14.6 \\
\hline Rural-Rural & 53 & 19.9 & 9 & 4.5 \\
\hline Urban - Abroad & 2 & 0.7 & 95 & 47.7 \\
\hline Urban - Rural & 98 & 36.7 & 12 & 6.0 \\
\hline Urban - Urban & 41 & 15.4 & 15 & 7.5 \\
\hline Sum & $\mathbf{2 6 7}$ & $\mathbf{1 0 0}$ & $\mathbf{1 9 9}$ & $\mathbf{1 0 0}$ \\
\hline
\end{tabular}

Governorate, while individuals often migrate to Europe. This trend of migrating abroad in the individual migration map is

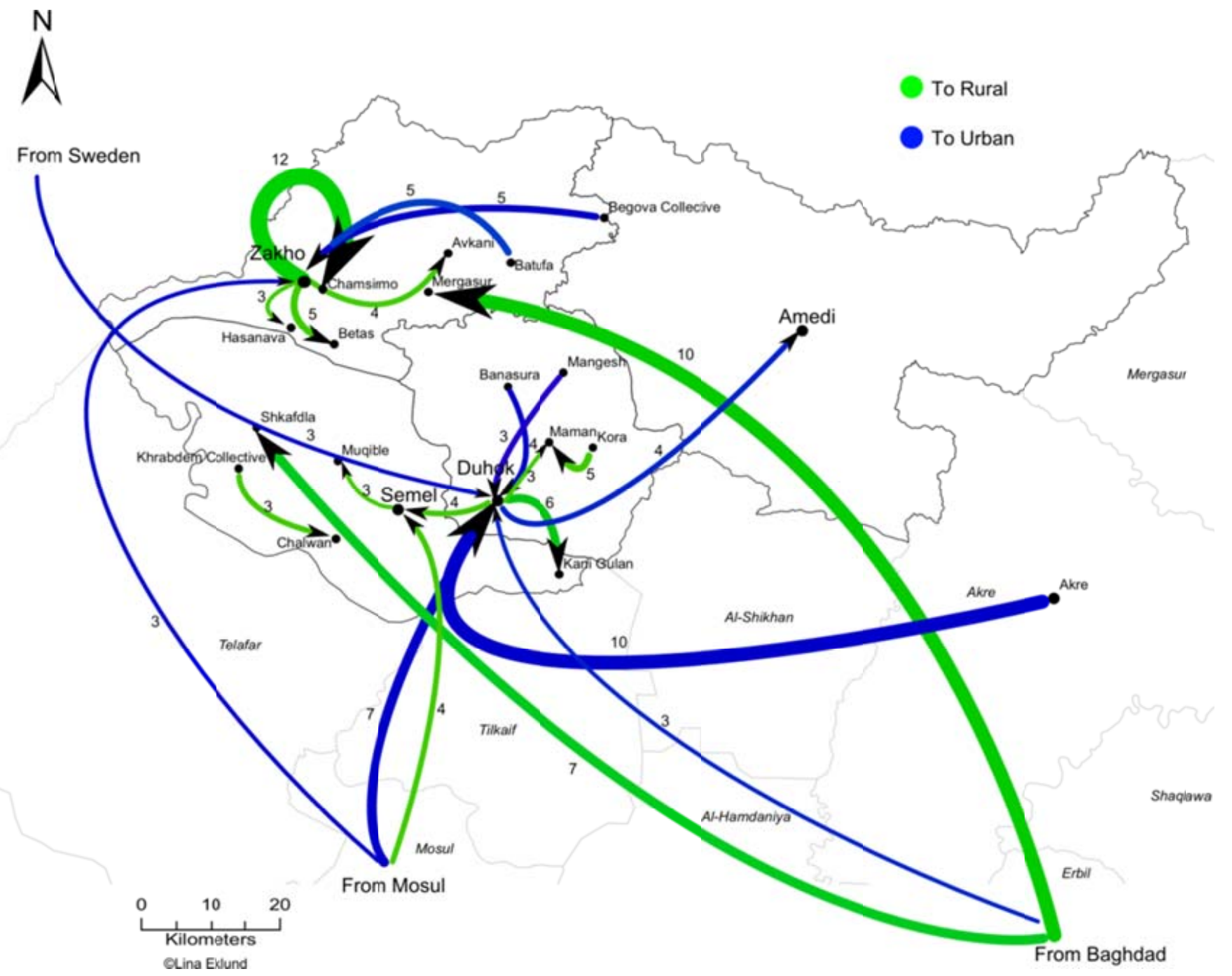

Fig. (4). Household migration patterns within and to Duhok Governorate 2000-2010. Numbers and thickness of arrows represent the number of migrant households. 


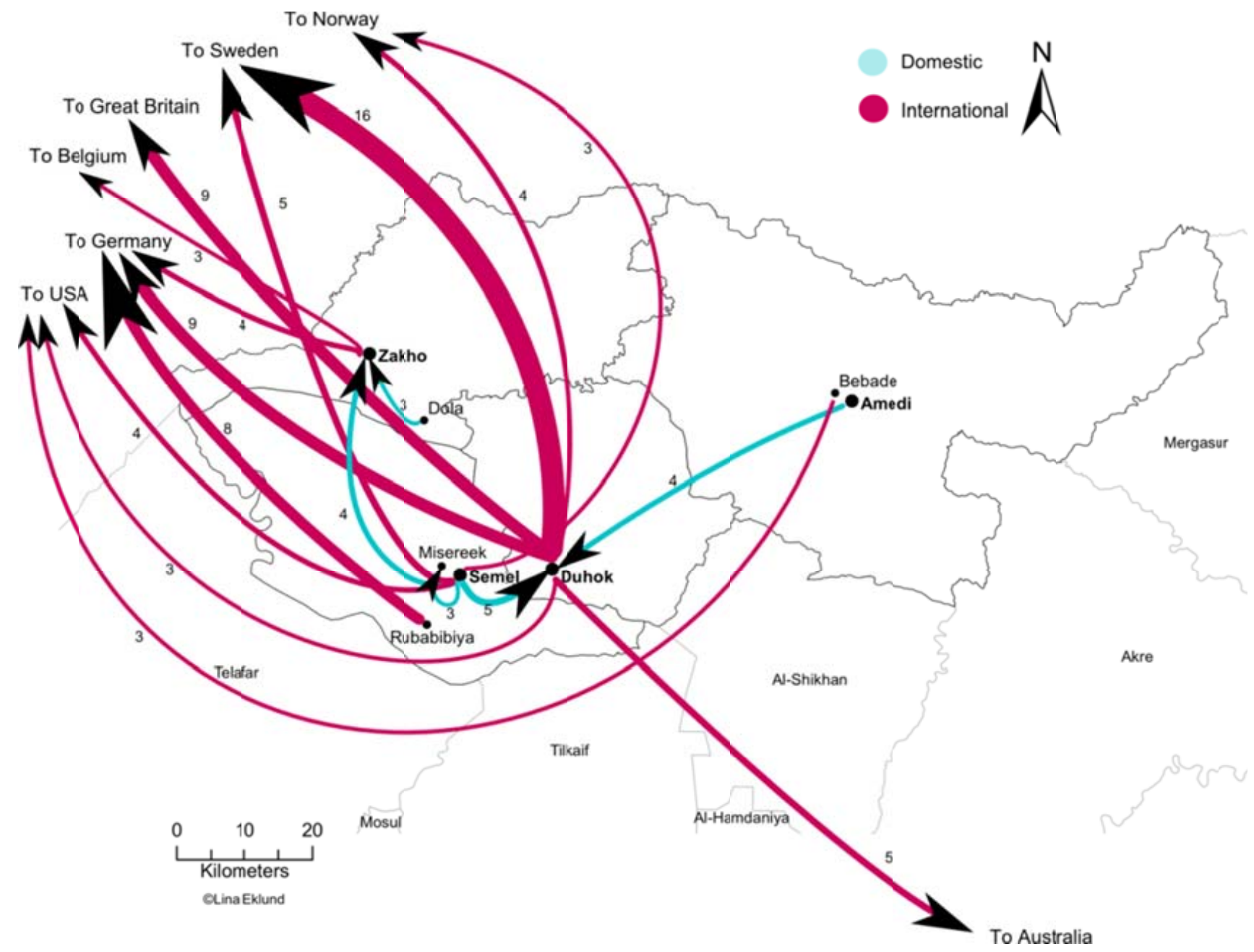

Fig. (5). Individual migration patterns within and from Duhok Governorate 2000-2010. Numbers and thickness of arrows represent the number of migrants.

more obvious than any trend in the household migration map. The pattern of household migration is much more irregular and complex, possibly because this map shows the migration within and to Duhok Governorate rather than within and from, as is the case for the individual migration map.

Individual migration is highly dominated by international and rural to urban migration. As proposed in the introduction (Section 1.1), the rural to urban migration might be a prelude to international migration. Our results show that most (individual) migration abroad, though not all come from urban centers (Fig. 4), and thus can be considered to support this theory.

\subsection{Security Migration}

It is clear that an increase in instability causes an increase in mobility. For example, the 260 households that temporarily relocated in 2003 show that in times of insecurity people are willing to temporarily leave their residence and seek stability. The number of these reported events, and their convergence in time, also prove the validity of the survey. The fact that none of these events were recorded in Amedi, and that some households even relocated to Amedi, can be explained by the physical properties of Amedi. The city is located on a mesa, a plateau with steep slopes on all sides. This slight isolation is likely to make Amedi less exposed to instability and internal problems in Iraq.

Between the years 2000 and 2010, 31 households have moved from Baghdad to Duhok Governorate and of these, $97 \%$ did so for security reasons. One third of the households also reported economy to be one reason for migration. The majority $(70 \%)$ ended up in rural communities, while the rest moved from Baghdad to urban areas, mainly Duhok. The main migration from Baghdad to Duhok Governorate happened between 2003 and 2007 (Fig. 6).

From Mosul 22 households have migrated in the last 10 years. Approximately $90 \%$ of the migration from Mosul is due to security reasons, while other reasons reported are economic and environmental. Similar to Baghdad, Mosul has seen an increased migration between the years 2003 and 2007. The migration from Baghdad and Mosul to Duhok Governorate is illustrated in Fig. (6).

The security migration from Baghdad and Mosul shows a decreasing trend of migration from Baghdad, and a slightly 


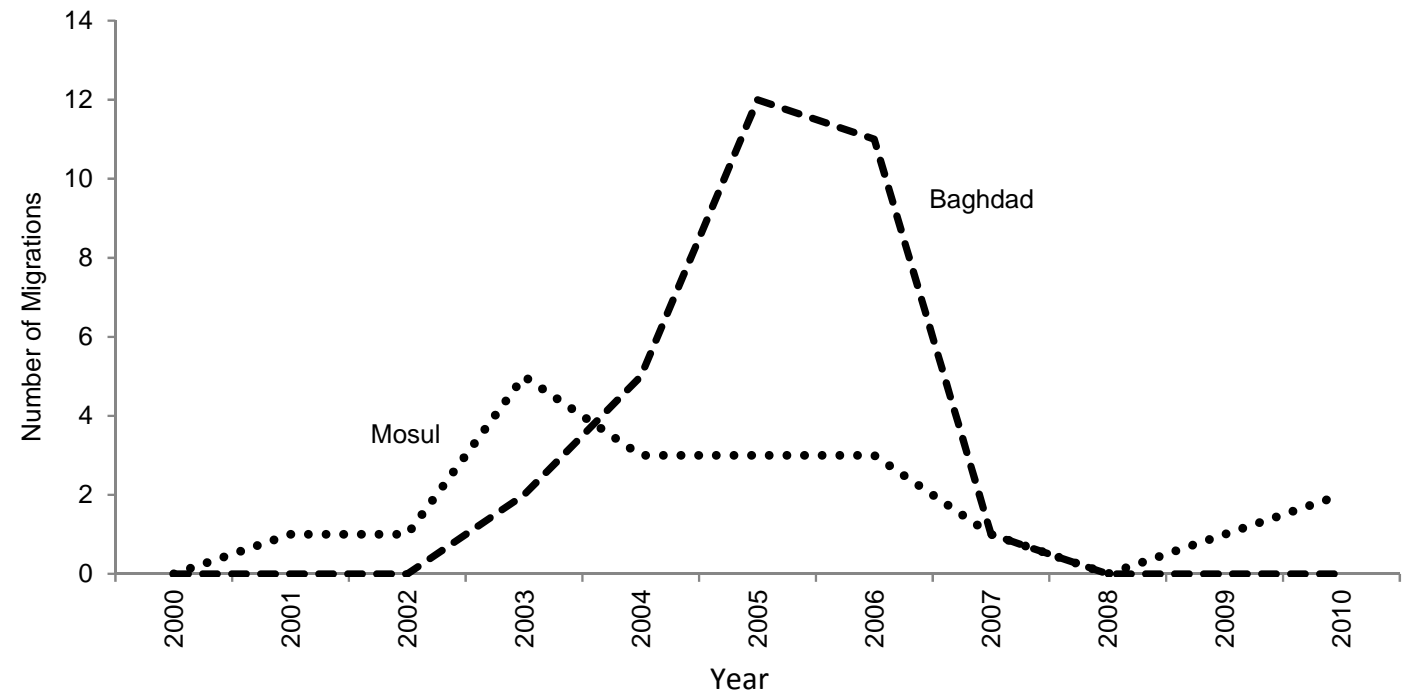

Fig. (6). Migration of households from Baghdad and Mosul to Duhok Governorate 2000-2010 (n=51).

increasing trend from Mosul. This only depicts BaghdadDuhok and Mosul-Duhok migration, since migration to other governorates in Iraq was not recorded. The indicated increase in migration from Mosul might be explained by the increasing sectarian violence that has been seen in the last years.

\subsection{Environmental Migration}

Only ten migration events were found where the reason "Environmental Degradation" was reported, as can be seen in Fig. (2). Out of these ten, only three had environmental degradation as the only reason for migration. In most cases, environmental reasons were combined with economy, family/marriage, education or security. Nine of the migration events were households that migrated, while one was an individual (male).

People involved in agriculture are the most likely to be affected by environmental change, such as drought or erosion. Involvement in agriculture in rural areas of Duhok
Governorate is in total less than $20 \%$, and only $13 \%$ are completely dependent on agriculture for income (Fig. 7). This leads to a low vulnerability of rural households to environmental changes. Many respondents reported that there is no benefit in agriculture due to the fact that the Government imports agricultural products from other countries, and therefore people try to find a more reliable income. This can be an important reason for the low frequency of environmental migration in the study area.

In this study, and possibly in many other studies, the environmental migration seems to be closely related to economic factors. If a household with agriculture as the main income is forced to move because of loss of yield they might perceive this as an economical reason and might not identify it as an environmental reason if not asked particularly about it. However, the results imply that the environment and climate did not cause significant problems for the rural population of Duhok Governorate during the last decade.

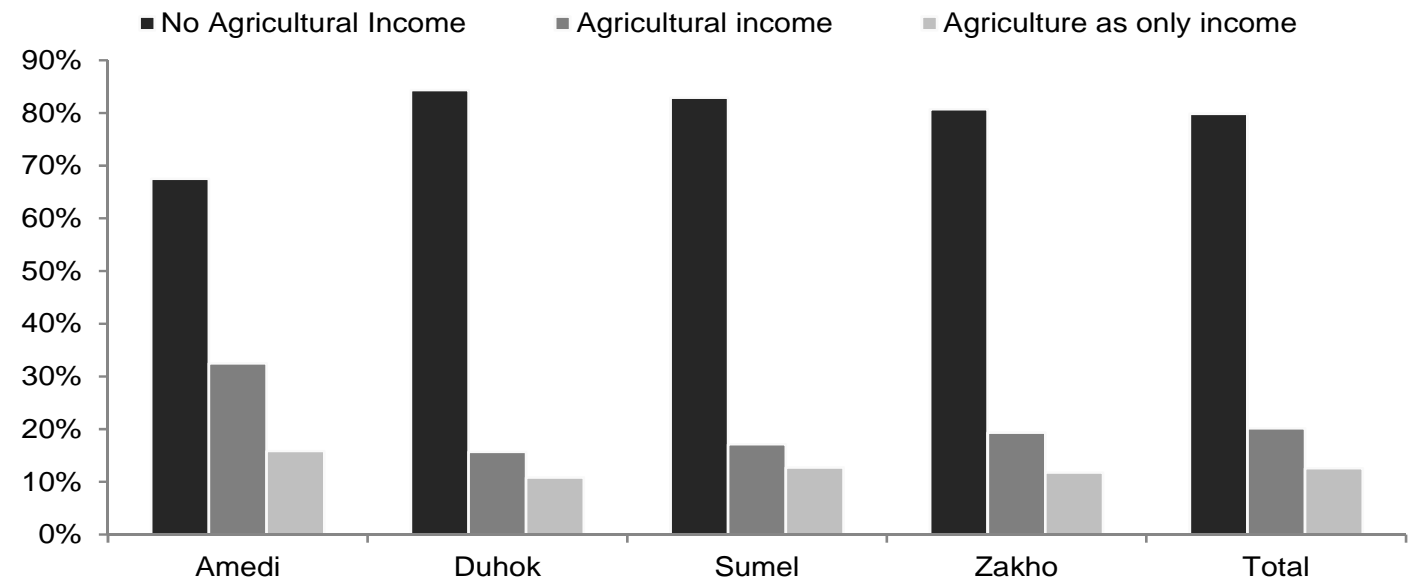

Fig. (7). Rural livelihoods in Duhok Governorate. The chart shows the proportion of the respondents in the rural household s reporting to have an income based partly or solely on agriculture. 


\subsection{Limitations}

Sampling always creates the question of whether or not the sample gained represents the whole population. This question particularly relevant when the situation does not allow interviews with the whole population (as it is in most cases of research) but only a relatively small number of respondents. In this study the number of interviews and the distribution of interviews in both rural and urban areas should provide a fair representation of Duhok Governorate. The interviews were conducted by local assistants who know the area, the language, and the culture well.

A limitation is the fact that almost all data are interview based, which increases the risk for misinterpretations. Respondents might misinterpret the question, interviewers might misinterpret the response, and the data analyst might misinterpret the response written down by the interviewer. These limitations call for flexibility in interviewing and data analyzing, where any obscurities have been cleared out by asking more questions to make sure that the interpretation is as correct as possible. In Iraq, as well as in many other countries, interviews are the only way to gain migration data, since no records are kept by administrative organizations, such as municipalities or governmental offices.

The question of having open-ended or closed questions is one that could be discussed. While open-ended questions might decrease bias from the researcher/questionnaire designer, it might also increase the risks for misinterpretations. Close-ended questions on the other hand have the benefit of being quicker, with a smaller risk of misinterpretations, but with the deficiency that only the expected answers are on the list. To decrease the latter problem, there was always the option "other" for the close ended questions, where it was possible to specify the answer.

Another important issue is the difference between households and individuals in terms of how the information about their migration events was collected. The information about the households' migration events usually comes from first hand sources, i.e. someone in the migrant household is responding to the questions. Information about individual migration, however, comes from second hand sources, mainly family members. Furthermore, the households' outmigration from the study area is not covered because only households residing in Duhok Governorate were surveyed. To gain comparable information about out-migration of households, the study area would have to be expanded to the whole world in order to find the households that left Duhok, and get detailed information about them. One question in the survey sought to bridge this gap, asking about nearby households that had migrated in the past 10 years. The results of this question were however inconsistent and deficient, and were therefore not included in this report.

\section{CONCLUSIONS}

The results of this study show the general patterns of migration in, to, and from Duhok Governorate during the last decade. It shows a population of high mobility due to mainly economic, family and marriage, or security reasons. The patterns found highlight the problems and opportunities in the areas of destination and origin. As an example, the security migration from Baghdad and Mosul indicates that
Duhok has during the past decade been a more stable place than many other areas in Iraq. Our findings have led to new questions that will help in formulating future research ideas and provide guidance for migration and development research in Duhok and surrounding areas. The most important ones are presented below.

It has been shown that households have a larger urbanrural migration than the rural-urban migration, a result that contradicts reports suggesting increased rural to urban migration and urbanization. This should be further investigated, looking into why households choose to move to rural areas, if there is an actual de-urbanization trend and what kind of consequences that would have for the rural landscape.

The individual migration differs largely from the household migration, where individuals are attracted by opportunities abroad, mainly to Europe. The ones moving to other countries usually have their homes in urban areas, while the ones originating from rural areas tend to migrate to urban areas. However, the rural-urban migration of individuals is even smaller than the same migration type of households, and should not be considered an urbanization factor.

This paper bridges an important gap in migration research, on the Middle East and in general, where most research is focused only on the international migration patterns. We have taken into account both external and internal migration, and have found the latter to be the most important type. Knowing the patterns and trends in internal migration could potentially help explaining some of the external migration. The common divide between internal and external migration is also too broad and not reflecting the social and economic costs of migration. Moving from a village on one side of the border to another village on the other side of a border is not comparable to moving from one continent to another. We therefore suggest further research on migration distances and the related reasons. What drives or attracts migrants to areas as far as one thousand kilometers from their homes? What migration distances will a drought cause? Or an economic depression? These are all questions that we would like to respond to in our future research.

Environmental migration is relatively small and arguably connected to, or concealed in, economic migration. We suggest that the small economic relevance of agriculture in rural areas, and thus the fact that few households are dependent on nature for their survival, lowers the vulnerability to environmental problems and hence decreases environmental migration. Although we have found some possible reasons, we need to investigate this further and in more detail. What impact has recent environmental problems had on migration patterns, and if they had none, why? And why is the rural population less involved in agriculture? Is it a coping mechanism to avoid having to migrate?

The rural areas of Duhok Governorate are, despite low agricultural activity, becoming more important demographically. This calls for an increased focus on rural areas in terms of research and development investments in infrastructure and social welfare. This would create even more opportunities in rural areas, leading to a continuing 
migration from urban to rural areas that might help decreasing the high demographic pressure on urban areas.

\section{ACKNOWLEDGEMENTS}

This research was conducted through the Middle East in the Contemporary World (MECW) project funded by the Swedish Research Council. We thank Professor Dr. Nazar Numan and Dr. Dawood Atrushi at University of Duhok for facilitating the field work and putting us in touch with the right people. We thank the field assistants in Iraq: Niwar Ameen Obaid, Shawkat Mohammad; Zinar Mosa Rasheed; Shamal Younis Yassin; Rayan Tatarkhan Sleman, and Ahmed Abbas Ahmed for their help with interviews. We thank Basheer Saeed and Hosein Hamid for their 24/7 assistance during and after the field work. Finally, we thank Darcy Thompson, Johan Toresson and Anna Eklund Norman for proofreading the manuscript.

\section{CONFLICT OF INTEREST}

Declared none.

\section{REFERENCES}

[1] Castles S, Miller M. The age of migration: international population movements in the modern world. $4^{\text {th }}$ ed. New York: Guilford Publications 2009.

[2] Sirkeci I. War in Iraq: environment of instecurity and international migration. Int Migr 2005; 43(4): 197-214.

[3] Cockburn P. UN warns of five million Iraqi refugees, 2007, The Independent.

[4] International Organization for Migration (IOM), IOM needs assessment. Post February 2006 Displacement in Iraq 2008.

[5] Lee ES. A theory of migration. Demography 1966; 3(1): 47-57.

[6] King R, Skeldon R. 'Mind the Gap!' Integrating approaches to internal and international migration. J Ethn Migr Stud 2010; 36(10): 1619-46.

[7] Borjas GJ. Economic theory and international migration. Int Migr Rev 1989; 23(3): 457-85.

[8] Boyd M. Family and personal networks in international migration: recent developments and new agendas. Int Migr Rev 1989; 23(3): 638-70.

[9] Brown O. Migration and Climate Change. IOM Research Series, No. 31, International Oorganization for Migration 2008. Geneva.
[10] Laczko F, Aghazarm C. Introduction and overview: enhancing the knowledge base, in migration, environment and climate change assessing the evidence. In: Laczko F, Aghazarm C, Eds. Geneva: International Organization for Migration 2009; pp. 9-38.

[11] Barney C. Urban growth in developing countries: a review of current trends and a caution regarding existing forecasts. World Dev 2004; 32(1): 23-51.

[12] Ibrahim SEM. Over-urbanization and under-urbanism: the case of the Arab world. Int J Middle East Stud 1975; 6(1): 29-45.

[13] United Nations department of economic and social affairs. World urbanization prospects. The 2009 Revision. 2009 [cited: 2011 November 7]; Available from: http://esa.un.org/unpd/wup/index. htm. [cited: 14 Dec 2011]

[14] United Nations Assistance Mission for Iraq (UNAMI). Joint key messages - World Water day 2011.

[15] Harris N. Migration and development. Econ Polit Wkly 2005; 40(43): 4591-5.

[16] Willis K. Introduction: mobility, migration and development. Int Dev Plann Rev 2010; 32(3/4): i-xiv.

[17] De Haas H. Migration and development: a theoretical perspective1. Int Migr Rev 2010; 44(1): 227-64.

[18] Kurdistan Regional Government (KRG). About Kurdistan region: contemporary history, K.R. Government 2010.

[19] United Nations Development Programme, Drought - Impact Assessment, Recovery and Mitigation Framework and Regional Project Design in Kurdistan Region (KR), 2010.

[20] Kurdistan Regional Statistics Office. Administration Units in Kurdistan Region. 2011; Available from: http://www.krso.net/. [cited 22 Nov 2011]

[21] Food and Agriculture Organization of the United Nations (FAO), Rural Household Survey In Iraq 2004.

[22] Cosit. Estimated Population By Governorates. Urban/rural and gender for the year 2009. Available from: http://cosit.gov.iq/engl ish/index.php. [cited: 25 Nov 2011]

[23] Bilsborrow R. Collecting data on the migration-environment nexus in migration, environment and climate change - assessing the evidence. In: Laczko F, Aghazarm C, Eds. Geneva: International organization for migration 2009; pp. 115-76.

[24] World Gazetteer. Iraq: largest cities and towns and statistics of their population.; Available from: http://www.world-gazetteer.com/ [cited: 7 Oct 2011]

[25] The Inkscape Team, Incscape 0.48, 2011.

[26] Environmental Systems Research Institute (ESRI), ArcGIS 10, 2010.

[27] Fan CC, Youqin H. Waves of rural brides: female marriage migration in China. Ann Assoc Am Geogr 1998; 88(2): 227-51.

(C) Eklund and Pilesjö; Licensee Bentham Open.

This is an open access article licensed under the terms of the Creative Commons Attribution Non-Commercial License (http://creativecommons.org/licenses/by$\mathrm{nc} / 3.0 /$ ) which permits unrestricted, non-commercial use, distribution and reproduction in any medium, provided the work is properly cited. 